\title{
Seismic and inter-seismic ground surface deformations of the Murono mud volcano (central Japan): a laser scanning approach
}

\author{
Yuichi S. Hayakawa ${ }^{1 *}$, Shigekazu Kusumoto ${ }^{2}$ and Nobuhisa Matta ${ }^{3}$
}

\begin{abstract}
A small mud volcano in Murono, Niigata Prefecture, north-central Japan, shows active ground surface displacements, not only when large earthquakes occur in the region but also during quiescent periods between earthquake events. The site recently underwent abrupt deformations due to strong regional earthquakes in 2004, 2007, 2011, and 2014, while gradual surface deformations were reported during quiescent periods between the earthquakes. To detect the spatial distribution of the changes in the mud volcano's ground surface elevation, we carried out multi-temporal terrestrial laser scanning. Point cloud datasets were registered at different times by minimizing the distance between the closest points in different clouds for stable ground features, which revealed centimeter- to decimeter-scale deformations around the domain of the conspicuous uplift. The spatial distribution of the deformation triggered by the earthquakes, including both central uplift and peripheral subsidence, exhibits an elliptical pattern, on which open crack fractures, associated with the earthquake-triggered uplift, were formed. The displacement and stress fields for the earthquakes were modeled numerically, and anomalously high pressure and/or weakening of the surficial materials was expected for the formation of fractures in the local domain. In contrast, continuous uplift was observed during the inter-seismic quiescent periods, the domain of which seems to have changed after the strong earthquake in 2014. In the coming years, further measurements will be necessary to unravel the physical subsurface mechanics of the mud volcano.
\end{abstract}

Keywords: Mud volcano, Terrestrial laser scanning, Point cloud, Digital elevation model, Cracks

\section{Introduction}

Mud volcanoes are characteristic landforms that occur in both subaerial and submarine areas, formed by the cumulative extrusion of liquid mud (Brown 1990; Hovland et al. 1997; Kopf 2002). There are thousands of onshore and offshore mud volcanoes on the Earth (Milkov 2000; Dimitrov 2003), which vent liquid mud, water, gas, and (occasionally) oil, either periodically or continuously (Hovland et al. 1997). Mud volcanoes are recognized as a significant source of gas emissions, including carbon dioxide and methane, into the atmosphere. This emitted gas is supplied from deeply buried sediments (Dimitrov 2002, 2003; Milkov 2005) and may contribute to global climate change (Etiope 2005; Judd

\footnotetext{
* Correspondence: hayakawa@csis.u-tokyo.ac.jp

${ }^{1}$ Center for Spatial Information Science, The University of Tokyo, 5-1-5

Kashiwanoha, Kashiwa, Chiba 277-8568, Japan

Full list of author information is available at the end of the article
}

2005). The chemical and isotopic components of the mud, which include water and oil, can be an indicator of natural resources such as petroleum (Kopf 2002; Milkov 2005) and can be strongly affected by near-surface (several to tens of kilometers in depth) geological structures, particularly in compressive tectonic zones (Martinelli and Dadomo 2005b; Feyzullayev et al. 2005; Mazzini 2009).

The activity of mud volcanoes is strongly related to tectonic conditions such as the seismicity of the region (Panahi 2000, 2005; Martinelli and Dadomo 2005a; Mellors et al. 2007; Mazzini 2009). In many cases, large remote earthquakes trigger mud volcano eruptions (Chigira and Tanaka 1997; Mellors et al. 2007; Mori and Kano 2009). In rare cases, these eruptions can, in turn, trigger weak local earthquakes (Panahi 2005). Furthermore, surface deformation of and gas emission from mud volcanoes can occur not only periodically through 
the occurrence of earthquakes but also continuously in quiescent regimes (Dimitrov 2002; Etiope 2005; Moerz et al. 2005; Kusumoto et al. 2014). Among other factors, the surface deformation of mud volcanoes is one of the most distinct and clear indicators of their activity (Hovland et al. 1997). Therefore, investigating the morphological characteristics and dynamics of surface deformation is crucial in revealing the detailed mechanisms and future activity of mud volcanoes. In particular, although earthquake-triggered surface deformation of mud volcanoes is often obvious (e.g., Manga et al. 2009; Onishi et al. 2009; Rudolph and Manga 2012), inter-seismic deformation of mud volcanoes is relatively less well recognized, necessitating further investigation (Kusumoto et al. 2014).

The deformation of active mud volcanoes has been investigated using various approaches on a wide variety of scales (e.g., Kopf 2002; Wang and Manga 2010). For large mud volcanoes (on the scale of hundreds of meters to kilometers), surface deformation can be detected by long-range remote sensing techniques, including satellite interferometric synthetic aperture radar (InSAR) (Mellors et al. 2007; Fukushima et al. 2009; Antonielli et al. 2014), aerial photographs (Shakirov et al. 2004; Istadi et al. 2009), and airborne laser scanning (ALS) (Doshida et al. 2007). Detection of surface deformation of small mud volcanoes (smaller than hundreds of meters) requires finer measurements that may include leveling, total station, and the use of high-precision global navigation satellite system (GNSS) (e.g., Onishi et al. 2009; Kusumoto et al. 2014, 2015). Even these approaches are often limited in their ability to reveal the spatial variation of surface deformation because of the low spatial density of their measurement points. As an efficient approach for exploring spatially variable deformation of landforms, terrestrial laser scanning (TLS) has been applied to obtain high-definition topographic data by using dense point clouds on the ground surface (e.g., Heritage and Large 2009; Whitworth et al. 2006; Hayakawa and Oguchi 2016). TLS enables the detection of temporal changes in topography at millimeter to centimeter scales when the measurements are performed multiple times and the multi-temporal point clouds are accurately registered to each other (Lane et al. 2003; Teza et al. 2007; Olsen et al. 2009; Milan et al. 2011; DeLong et al. 2015). Thus, this approach is potentially advantageous in the detection of spatially variable surface deformation of small mud volcanoes, although such application of TLS on mud volcanoes has been limited so far.

Performing a preliminary analysis on TLS data, Hayakawa et al. (2016) measured temporal changes in the ground surface of a small mud volcano in Murono, central Japan, within an accuracy of centimeters. This study expands this analysis to a longer time period, including two major earthquakes that affected the study region, aiming to give a primitive discussion on the links between the surficial changes and subsurface fluid dynamics of the mud volcano, with and without the impact of earthquake events.

\section{Methods/Experimental \\ Study site}

The Murono mud volcano is located in Tokamachi City, Niigata Prefecture in north-central Japan (Fig. 1). The monthly mean air temperature ranges from $-0.2{ }^{\circ} \mathrm{C}$ in January to $24.9{ }^{\circ} \mathrm{C}$ in August, and the mean annual precipitation is $2496.7 \mathrm{~mm}$, about one third of which is supplied as snow in winter (Japan Meteorological Agency 2016). Many fold structures in the NE-SW direction are present in the area, and the study site is located in the vicinity of an unnamed anticline limb between the Gimyo anticline and the Naradate syncline (Noda 1962, Takeuchi et al. 2000) (Fig. 1b). The substrate rock in the study site is massive black mudstone of the Early Pliocene Sugawa Formation, which widely covers both the unnamed and Gimyo anticlines ( $\mathrm{Sm}$ in Fig. 1b). Younger rock formations (Late Pliocene to Early Pleistocene) appear toward the Naradate syncline southeast (Fig. 1b), while older rocks appear in the farther southeast areas, toward another major anticline (the Matsunoyama anticline, outside the map boundary of Fig. 1b). Because of such geological structures, there is abundant production of petroleum and natural gas, as well as hot springs in the area. The activity of the Murono mud volcano can be a key to unraveling the subsurface structure and mud flow dynamics in the area. As a result, various studies have been carried out involving this mud volcano using geodetic, geophysical, and geochemical approaches (e.g., Onishi et al. 2009; Shinya and Tanaka 2009; Suzuki et al. 2009; Etiope et al. 2011). While convex-up relief is commonly observed in large mud volcanoes that are hundreds of meters in length and tens of meters in height (Higgins and Saunders 1974; Chigira and Tanaka 1997), the small Murono mud volcano has a relatively flat surface, with a very small mound having a height of only decimeters.

The altitude of the site is about $316 \mathrm{~m}$ above sea level (a.s.l.), and the main active area of the mud volcano is approximately $130 \mathrm{~m} \times 180 \mathrm{~m}$ (Fig. 1c). The western side of the site is partially deformed, while the center of the site, which contains a vent, does not show obvious uplift (Kusumoto et al. 2014, 2015). In contrast, the eastern side has particularly large and frequent deformations. A portion of this side approximately $50 \mathrm{~m} \times 60 \mathrm{~m}$ (Fig. 1c) was selected as the target zone of this study.

In the last decade, large earthquakes have hit the region frequently, and the mud volcano has been significantly deformed by the strong jolts. Such deformations 


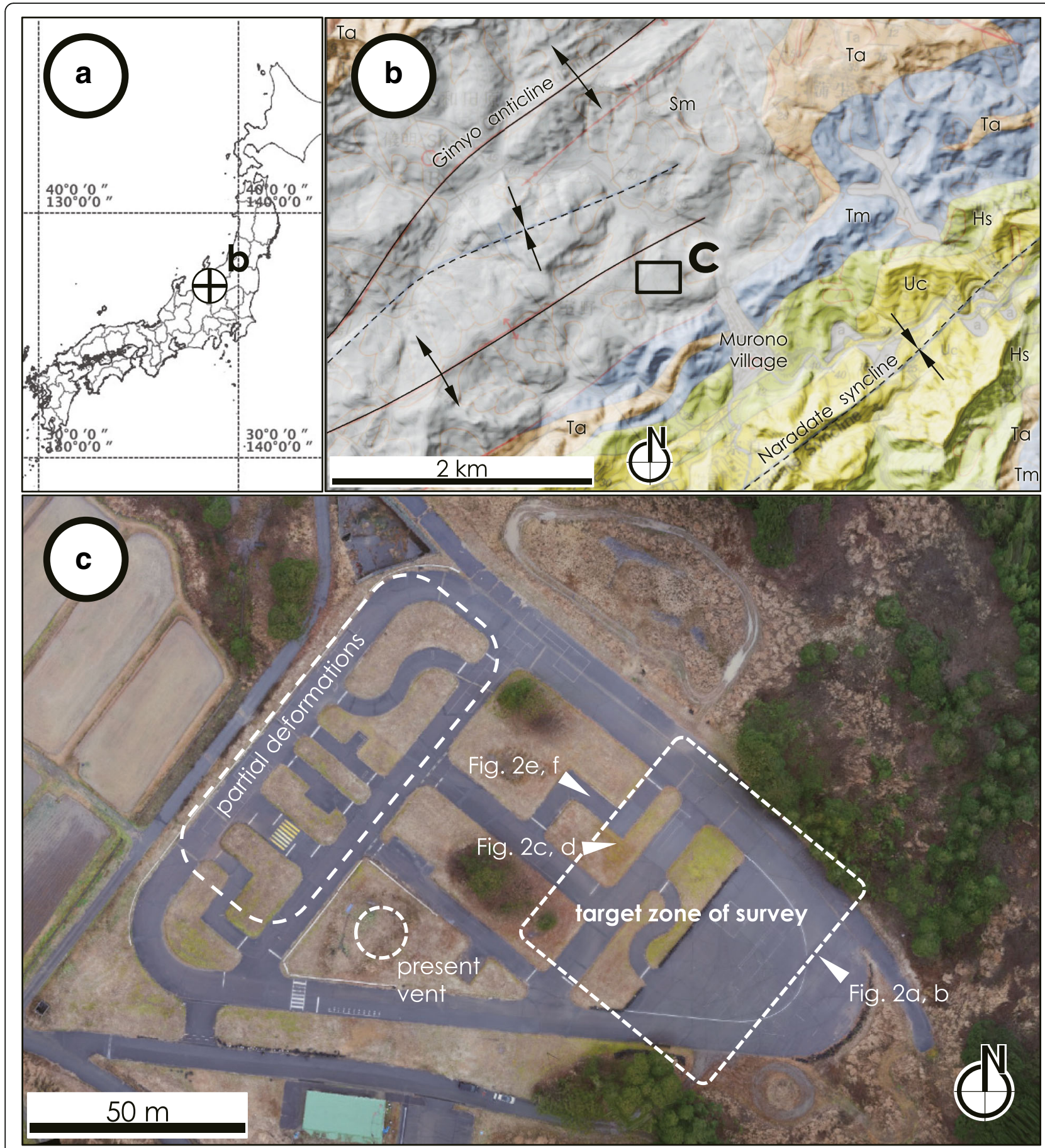

Fig. 1 Study area: Murono mud volcano. a Overview. b Regional view on a background of a 1:50,000 geological map (after Takeuchi et al. 2000) with topographic hillshade. Black solid and dashed lines indicate the anticline and syncline structures, respectively. Sm massive black mudstone of the Sugawa Formation (Early Pliocene), Tm, Ta, Ts massive siltstone, interbedded sandstone and siltstone, and thick-bedded sandstone, respectively, of the Tamugigawa Formation (Late Pliocene), Hs interbedded sandy siltstone of the Higashigawa Formation (Late Pliocene), Uc marine sand with gravel of the Uonuma Formation (Late Pliocene to Early Pleistocene). c Aerial image of the study site. The present vent of the mud volcano is at the center, and this study's target zone is located in the eastern side of the area. Triangular arrows indicate locations and directions of photographs shown in Fig. 2

of the site have been investigated by different methods of topographic measurements, including GNSS, leveling, and TLS surveys. At the time of the Niigata-ken
Chuetsu-oki Earthquake $\left(M_{w}=6.6\right.$, epicenter $44 \mathrm{~km}$ away from the site) in July 2007, the maximum acceleration at a monitoring station near the site (NIG021- 
Tokamachi, $21 \mathrm{~km}$ away) was recorded to be $3.02 \mathrm{~cm} / \mathrm{s}^{2}$ (National Research Institute for Earth Science and Disaster Resilience 2016). Although there was the Niigata-ken Chuetsu Earthquake in October $2004\left(M_{w}=6.7\right.$, epicenter $33 \mathrm{~km}$ away from the site) with the maximum acceleration of $17.5 \mathrm{~cm} / \mathrm{s}^{2}$ at NIG021, the influence of this earthquake on the mud volcano is unknown.

Onishi et al. (2009) performed extensive GNSS surveys at the site with more than 4000 measurement points over the paved ground surface in June 2006 and September 2008. Although the direct influence of the 2007 earthquake is unknown due to the 1 year time lag between earthquake and the later measurement, it was assumed that the amount of vertical deformation of the mud volcano during this period was closely related to the 2007 earthquake. According to the widespread GNSS measurements, the cumulative vertical deformation of the ground surface in the period from 2006 to 2008 was spatially variable: the maximum uplift was observed to be approximately $400 \mathrm{~mm}$ near the central portion of the mud volcano (the northwestern half of the surveyed target zone; Fig. 1c), while the easternmost side of the mud volcano (the southeastern half of the surveyed target zone; Fig. 1c) showed less uplift (<100 mm) (Onishi et al. 2009). The area of high uplift is spatially correlated with a high attenuation zone for ground penetrating radar (Yokota et al. 2008), indicating the presence of very shallow mudstone layers decomposed into soft clay with high water content. On the other hand, the area with less uplift correlates well with a zone of high $\mathrm{S}$-wave velocity in a very shallow $(<20 \mathrm{~m}$ deep) area (Onishi et al. 2009), likely unaffected by the mud volcano activity.

The North Nagano Prefecture Earthquake $\left(M_{w}=6.4\right.$, epicenter $16 \mathrm{~km}$ away, maximum acceleration of $3.08 \mathrm{~cm} / \mathrm{s}^{2}$ ) in March 2011 and the Nagano-ken Kamishiro Fault Earthquake $\left(M_{w}=6.7\right.$, epicenter $76 \mathrm{~km}$ away, maximum acceleration of $0.22 \mathrm{~cm} / \mathrm{s}^{2}$ ) in November 2014 also caused remarkable vertical deformations of greater than $200 \mathrm{~mm}$ (revealed by laser scanning) and $46 \mathrm{~mm}$ (by leveling survey), respectively (Matta et al. 2012; Kusumoto et al. 2015; National Research Institute for Earth Science and Disaster Resilience 2016). Vertical deformation continues even in the interseismic period with seasonal variations of about $\pm 5 \mathrm{~mm}$, revealed by leveling surveys (Kusumoto et al. 2014). Although it is known that the land manager repaired the ground pavement after distinct cracks were identified subsequent to the earthquakes (Fig. 2), we suppose that artificial modifications had only limited effects on the surface elevation because their purpose was only to replace the fractured pavement, which would not change the surface elevation significantly. Indeed, the fractures formed in 2011 (Fig. 2a, c, e) are almost as clean as observed in 2013 (Fig. 2b, d, f), but the pavement surface was not truly flattened and the uplifted deformations surrounding the paved surface remain.

\section{Data acquisition and analysis \\ Topographic measurements by terrestrial laser scanning}

Field surveys were carried out four times between June 2011 and November 2015. The North Nagano Prefecture Earthquake (March 2011) occurred before any of these surveys, and the Kamishiro Earthquake (November 2014) occurred just before the third one.

The terrestrial laser scanners used for the measurements include a Topcon GLS-1500 scanner for the first set of measurements in 2011 and Trimble TX5 scanners for the other measurements in 2013 to 2015 . The GLS-1500 is a medium-range scanner, with a maximum measurable distance of $500 \mathrm{~m}$ at a scan rate of 30,000 points per second and a range accuracy of $4 \mathrm{~mm}$ within $150 \mathrm{~m}$ of the unit (Topcon 2010). The TX5 is a lightweight short-range scanner with phase-based laser ranging capability, with a maximum measurable distance of $120 \mathrm{~m}$ at a maximum scan rate of 900,000 points per second, and a range accuracy of $0.3-1.1 \mathrm{~mm}$ at $10-25 \mathrm{~m}$ from the unit (Trimble Navigation Limited 2012). Topcon ScanMaster v.2.1 and Trimble RealWorks v.8.1 software, bundled with the scanners, were used for the data processing of the point clouds. Both scanners have the ability to adjust their horizons using built-in inclination sensors.

Because laser emissions are directional, measurements taken from only one scan position may result in insufficient point cloud coverage with a large fraction of shadows in the data (Hayakawa and Oguchi 2016). In order to cover the target area correctly with a laser scanner, multiple scan positions should be set in the field at the time of each measurement. The point clouds from the different scan positions must then be registered and merged to obtain point cloud data coverage of the entire target zone (internal registration). For this, we apply a cloud-based registration method, which utilizes partial point clouds that represent key morphological features, including the ground surface of the target area, tree trunks, and poles in the surrounding area. In this cloudbased registration, the iterative closest point (ICP) algorithm is performed to minimize the distances between the nearest points on key features (Besl and McKay 1992; Bergevin et al. 1996). In this algorithm, a point cloud is iteratively transformed to fit another reference point cloud, based on overlapping areas with the same morphological features. The amount of error of the cloud-based registration depends primarily on the density of the points, and accuracy on the scale of several millimeters can be obtained if the point density has millimeter-scale spacing (e.g., Teza et al. 2007). The registered point clouds are all merged into one point cloud data point for each survey time. 

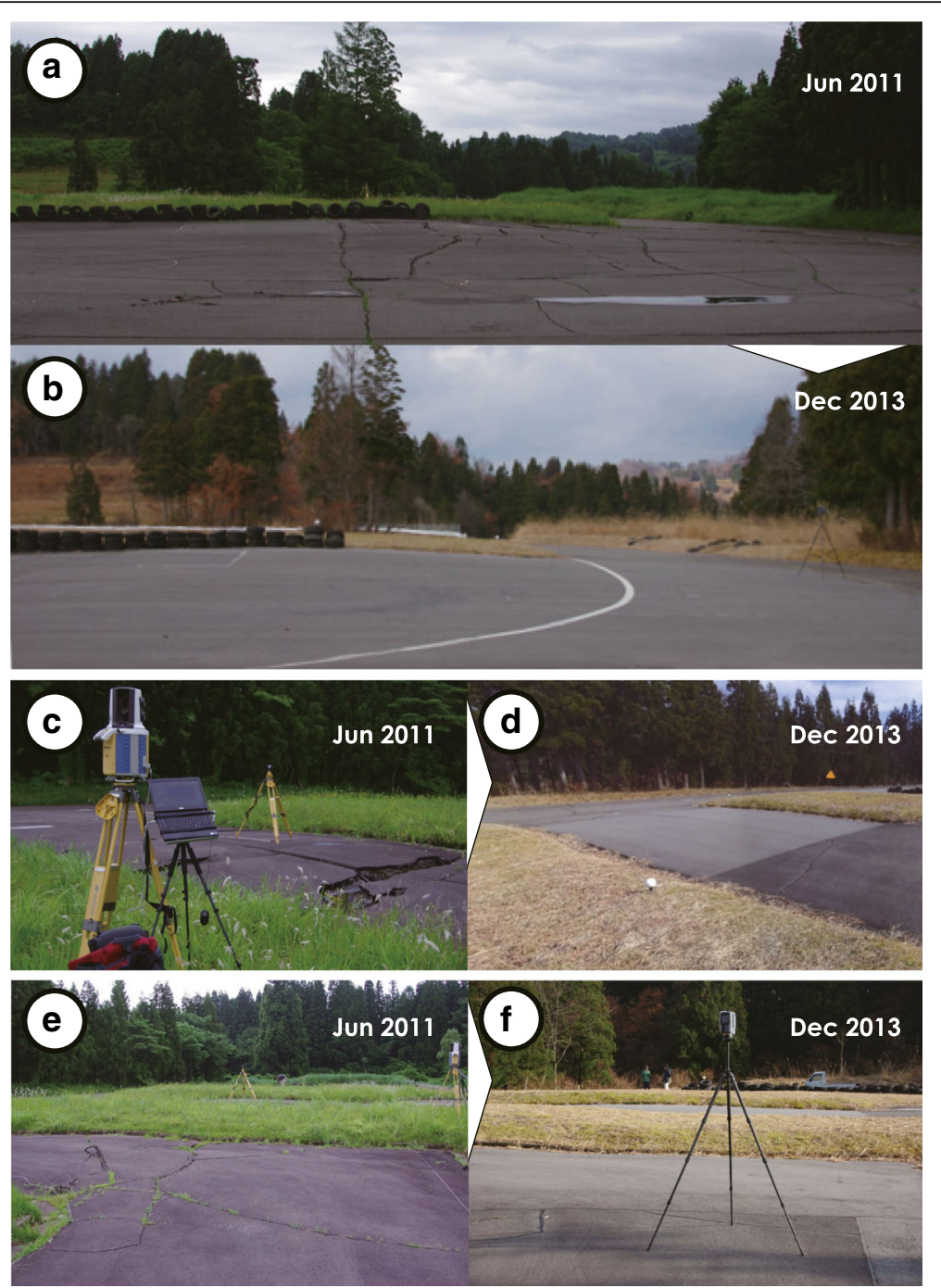

Fig. 2 Photographs of the site. $\mathbf{a}, \mathbf{c}$, e The open cracks on the surface pavement formed by the 2011 earthquake. $\mathbf{b}$, $\mathbf{d}$, f The repaired pavement. Photograph locations are shown in Fig. 1c

The georeference of the point clouds, i.e., the external registration of the merged point cloud onto geographical coordinates, was primarily performed using several target references whose geographical coordinates (in Universal Transverse Mercator (UTM) Zone 54N, JGD2000 datum) are obtained from GNSS measurements with the capability to post-process carrier-phase corrections. We used a Trimble GeoExplorer 6000XH as a receiver, and the positioning log data were corrected using data from nearby GEONET (GNSS network in Japan) base stations, provided by the Geospatial Authority of Japan. The fix solution provides centimeter-level accuracies for the GNSS positioning. However, GNSSbased georeferencing errors of point clouds often exceed centimeters, which restrict accurate comparison of the point clouds at different times. Therefore, we refined the alignment of the point clouds at different times by means of cloud-based ICP registration based on features that are thought to stay in the same location, and do not change shape, distributed around the target zone. For this process, the changing main target area of measurement is cropped out, and stable areas that do not include changes in surrounding areas, such as major tree trunks, electric poles, and buildings, are used for the alignment. The ICP procedure was repeatedly applied to refine the external registration to minimize the point-topoint distances between the clouds. The third measurement dataset in 2014 was set as the reference, as it had the most accurate GNSS-based georeferencing. Each of the other datasets was successively aligned to its adjacent dataset.

To examine the topographic changes in the ground surface at the target zone, the zone was first extracted from the original point cloud, while unnecessary points 
representing vegetation and other artificial objects such as buildings and poles were removed. Then, the digital elevation model (DEM), a two-dimensional raster dataset representing the topography projected on the UTM coordinates, was generated from the extracted point cloud. Geographic information system (GIS) software (ESRI ArcGIS 10.3) was used for the DEM data processing. The resolution of DEMs is determined based on the spatial density of their point cloud data. In the conversion from point cloud to DEM, a triangular irregular network (TIN) model is generated to perform linear interpolation for the randomly distributed points. Furthermore, areas far from the scanner position, that have insufficient point density, less overlapping scan coverage, or vegetation (mostly low-height plants, $<40 \mathrm{~cm}$ ) where the ground surface is hard to detect, were cropped out by setting a mask on the DEM and excluded from the following analyses. Three section lines were then set in the target zone to extract topographic profiles from the DEMs.

\section{Topographic data comparisons}

A $2 \mathrm{~m}$ resolution DEM, obtained by ALS and used as the initial condition of the comparative analysis with TLS data, was also used for topographic data comparisons. The ALS measurements were performed in July 2004 by Kokusai-Kogyo Co., and a filtered digital terrain model (DTM) was derived, showing the ground surface in the region after removing ground objects such as vegetation and buildings (Fig. 1b).

Differences in DEMs were then computed for each period between consecutive survey times. The four periods are defined as period I, 2004 to 2011; period II, 2011 to 2013; period III, 2013 to 2014; and period IV, 2014 to 2015.

\section{Crack mapping and numerical modeling of stress field}

Since the target zone exhibited apparent elliptical bulging of the ground surface with distinct open cracks in the paved surface at the time of the June 2011 measurement, the open cracks (fractures) were traced using the DEM generated for that time. Hillshade image and local variation of elevation calculated from the DEM $(3 \times 3$ cell statistics $)$ were supportively used to highlight the crack features to be manually extracted. The general orientation of the crack lines was then summarized. Cracks with orientations similar to those in 2011 were also visually observed at the time of measurement in December 2014, just after the Kamishiro Earthquake, although they could not be mapped because they were not distinctly open enough to be identified as a surficial shape in the point cloud.

We performed numerical modeling of the vertical displacement and stress fields for crack formation associated with the elliptical uplift. The vertical displacement field of a uniformly loaded elliptical plate with a clamped edge is given as follows (e.g., Timoshenko and Woinowsky-Krieger 1959):

$$
u_{z}=w_{0}\left(1-\frac{x^{2}}{a^{2}}-\frac{y^{2}}{b^{2}}\right)^{2}
$$

where $a$ and $b$ are the semi-major axis and semi-minor axes, respectively, and

$$
w_{0}=\frac{p}{D}\left(\frac{24}{a^{4}}+\frac{16}{a^{2} b^{2}}+\frac{24}{b^{4}}\right)^{-1} .
$$

In Eq. (2), $p$ is a load acting uniformly on the plate and $D$ is the flexural rigidity of the plate defined by the following equation:

$$
D=\frac{E h^{3}}{12\left(1-v^{2}\right)} \text {. }
$$

Here, $h, E$, and $v$ are the thickness, Young's modulus, and Poisson's ratio of the plate, respectively.

Since the horizontal displacement components of the vertical displacement are $u_{x}=-z\left(\partial u_{z} / \partial x\right)$ and $u_{y}=$ $-z\left(\partial u_{z} / \partial y\right)$ (e.g., Timoshenko and Woinowsky-Krieger 1959; Nakahara et al. 2001), the horizontal displacement fields at the surface $(z=h / 2)$ are given as follows:

$$
\begin{aligned}
& u_{x}=\frac{2 w_{0}}{a^{2}} h x\left(1-\frac{x^{2}}{a^{2}}-\frac{y^{2}}{b^{2}}\right), \\
& u_{y}=\frac{2 w_{0}}{b^{2}} h y\left(1-\frac{x^{2}}{a^{2}}-\frac{y^{2}}{b^{2}}\right) .
\end{aligned}
$$

Stress fields $\left(\sigma_{x}, \sigma_{y}, \sigma_{z}, \tau_{x y}, \tau_{y z}, \tau_{z x}\right)$ occurring on the plate surface caused by bending due to load $p$ are given as

$$
\begin{aligned}
& \sigma_{x}=\frac{3 p}{l h^{2}}\left[\frac{1}{a^{2}}+\frac{v}{b^{2}}-\frac{1}{a^{2}}\left(\frac{3}{a^{2}}+\frac{v}{b^{2}}\right) x^{2}-\frac{1}{b^{2}}\left(\frac{1}{a^{2}}+\frac{3 v}{b^{2}}\right) y^{2}\right], \\
& \sigma_{y}=\frac{3 p}{l h^{2}}\left[\frac{v}{a^{2}}+\frac{1}{b^{2}}-\frac{1}{a^{2}}\left(\frac{3 v}{a^{2}}+\frac{1}{b^{2}}\right) x^{2}-\frac{1}{b^{2}}\left(\frac{v}{a^{2}}+\frac{3}{b^{2}}\right) y^{2}\right], \\
& \tau_{x y}=\frac{-6(1-v)}{a^{2} b^{2} h^{2} l} p x y, \\
& \sigma_{z}=\tau_{y z}=\tau_{z x}=0,
\end{aligned}
$$

and $l$ is defined by

$$
l=\frac{3}{a^{4}}+\frac{2}{a^{2} b^{2}}+\frac{3}{b^{4}} .
$$

\section{Results and Discussion}

\section{Summary of topographic data}

Based on the land cover type (paved or vegetation) and the availability of data as shown by the overlapping TLS point clouds, the target area for the analysis $\left(2188 \mathrm{~m}^{2}\right)$ 
was defined on the paved ground surface (Fig. 3a). Figure 4 shows an oblique view of the point clouds, and Table 1 summarizes the properties of the four point clouds for each TLS measurement. The density of the point clouds in the area of interest ranges from 583.9 to $35,814.1$ points per square meter, which is equivalent to an average point spacing of 5.3-41.4 $\mathrm{mm}$. Consequently, the DEM resolution achievable from these point clouds is $50 \mathrm{~mm}$ for the 2011 data and $10 \mathrm{~mm}$ for 2013, 2014, and 2015.
The 2011 point cloud is relatively sparse compared to the others because of the limitations of the device used (medium-range GLS-1500 scanner). Although the point clouds from 2013 to 2015 were all obtained using the same TX5 short-range scanner, the point densities vary due to differences in the scanning settings and environmental conditions. Particularly, the relatively sparse densities for 2014 and 2015 are due to wet conditions on the ground surface from rain (Fig. 4c, d).
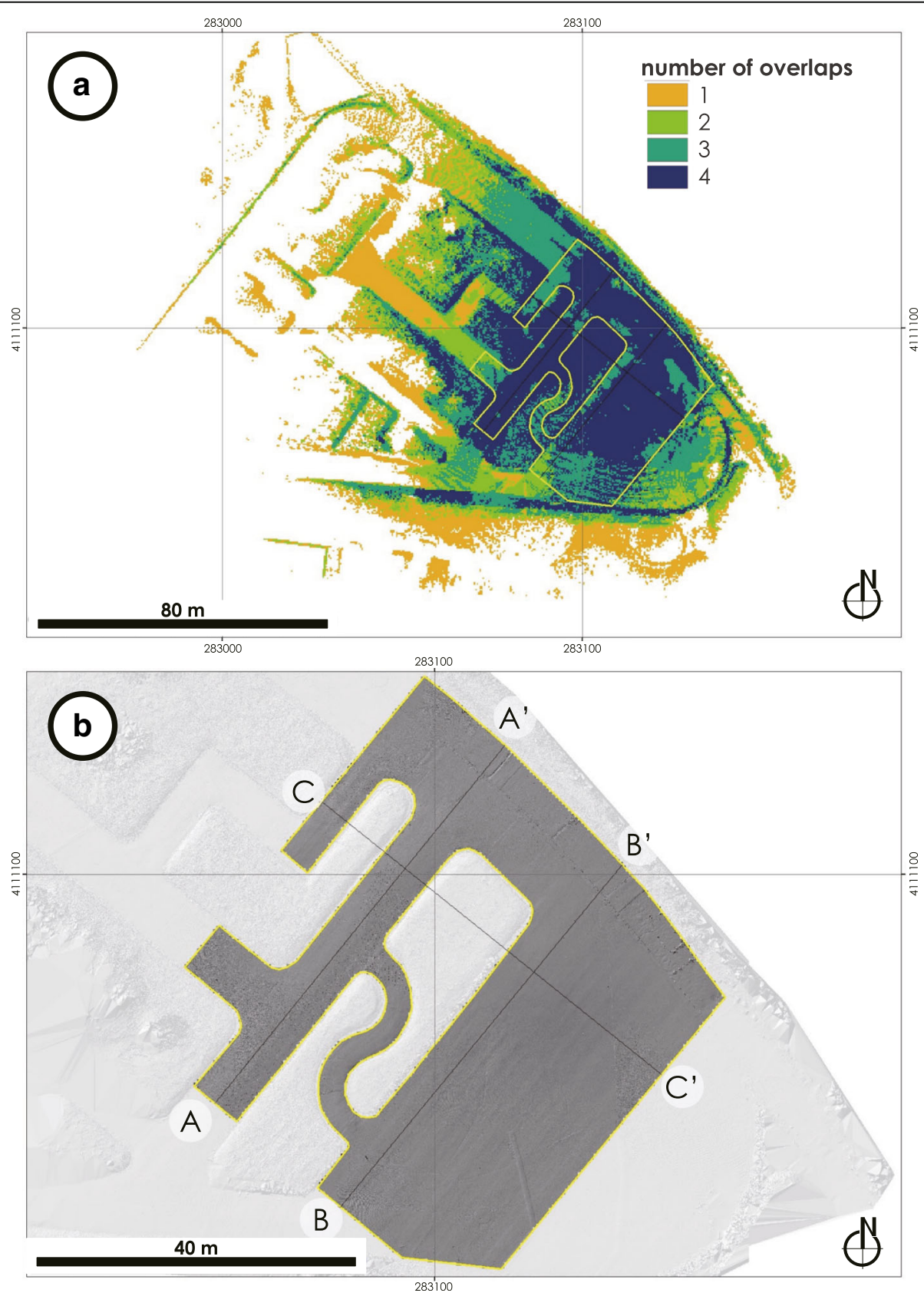

Fig. 3 Detailed view of the target zone in the Murono mud volcano. a Areas showing number of overlaps of the TLS measurements. The target zone is shown by a yellow polygon. b Location of the three profile sections (Fig. 7) in the target zone 

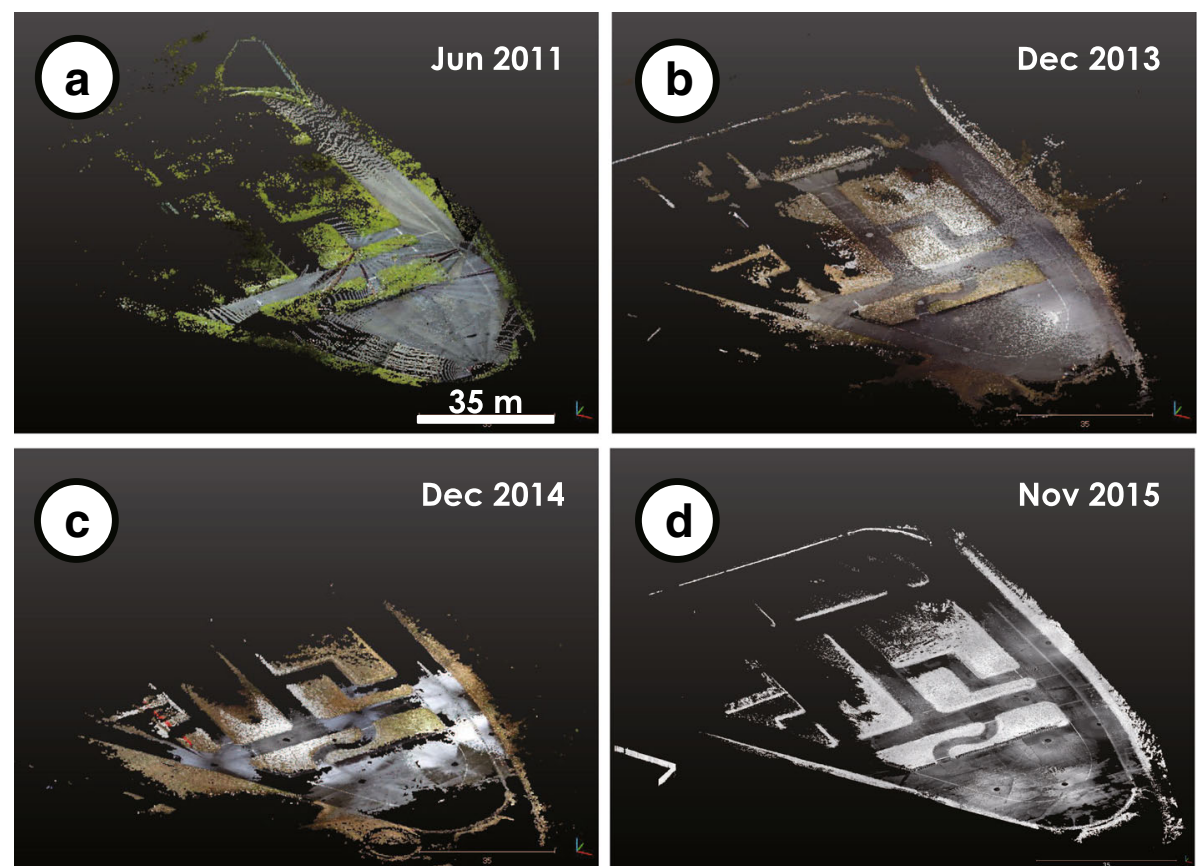

Fig. 4 Point clouds obtained by TLS in a 2011, b 2013, c 2014, and d 2015. The point clouds are shown in RGB colors, although the 2015 point cloud is in monochrome because color capturing was skipped in the field as there was insufficient sunlight after sunset

The accuracy of the internal registration ranges over 2.9-9.8 $\mathrm{mm}$, which is sufficiently small for the average spacing of the entire set of point clouds. As noted before, the third measurement dataset in 2014 was set as the reference, and each dataset was successively aligned to the adjacent dataset. The external registration errors from the ICP algorithm were $6.2-19.8 \mathrm{~mm}$ for this dataset. These are comparable to the previous accuracy assessment for TLS measurement at this site reported by Hayakawa et al. (2016). Changes in the land surface exceeding these values $(>20 \mathrm{~mm})$ are discussed in the following sections.

\section{Temporal changes in surface elevation}

Differences in the elevations of the DEMs, rasterized from the point clouds, were computed for each period.

Table 1 Properties of TLS-derived point clouds for each measurement

\begin{tabular}{|c|c|c|c|c|}
\hline Measurement occasion & 1 & 2 & 3 & 4 \\
\hline Year & 2011 & 2013 & 2014 & 2015 \\
\hline Date & Jun. 23 & Dec. 5 & Dec. 4 & Nov. 27 \\
\hline Terrestrial laser scanner used & GLS-1500 & TX5 & TX5 & TX5 \\
\hline Number of scan position & 4 & 8 & 7 & 10 \\
\hline Weather conditions & Cloudy & Sunny & Rainy & Rainy to cloudy \\
\hline Internal registration error (mm) & 4.0 & 2.9 & 7.9 & 9.8 \\
\hline Horizontal GCP error (mm) & - & - & 12.1 & 11.7 \\
\hline Vertical GCP error (mm) & - & - & 23.1 & 17.3 \\
\hline Number of GCPs & - & - & 11 & 3 \\
\hline External registration errors $(\mathrm{mm})$ & 6.2 & 15.7 & - & 19.8 \\
\hline Total number of measured points & $1,973,134$ & $130,137,112$ & $102,864,460$ & $47,933,335$ \\
\hline Number of points used & $1,082,832$ & $52,158,136$ & $69,169,926$ & $30,018,333$ \\
\hline Coverage area (excluding no data cells) $\left(\mathrm{m}^{2}\right)$ & 1854 & 2187 & 1931 & 2122 \\
\hline Point density $\left(\mathrm{pt} / \mathrm{m}^{2}\right)$ & 583.9 & $23,845.2$ & $35,814.1$ & $14,143.6$ \\
\hline Average point spacing (mm) & 41.4 & 6.5 & 5.3 & 8.4 \\
\hline
\end{tabular}


The centimeter-scale vertical changes in the ground surface appear to be spatially variable (Fig. 5). Figure 6 shows the histograms of surface elevation changes, displaying their aerial percentage for each period $(I-I V)$, and Table 2 shows the basic statistics (mean, standard deviation, 1st and 99th percentiles) and the mean rate of elevation change. Here, in order to avoid erroneous outliers, the 1st and 99th percentiles serve as proxies for the minimum and maximum values. Figure 7 illustrates the topographic profiles of the target area at the different times. The initial ground surface in 2004 appears to be relatively flat (Fig. 7), and changes in elevation around the dome-like uplift (Fig. 5) seem to accumulate, forming a symmetric pattern of profiles throughout the measurement periods (Fig. 7). On the other hand, the southeastern area is characterized by a continuous decrease in ground surface elevation since 2004 (Figs. 5 and $7 \mathrm{c}$ ). More details of the temporal changes in the

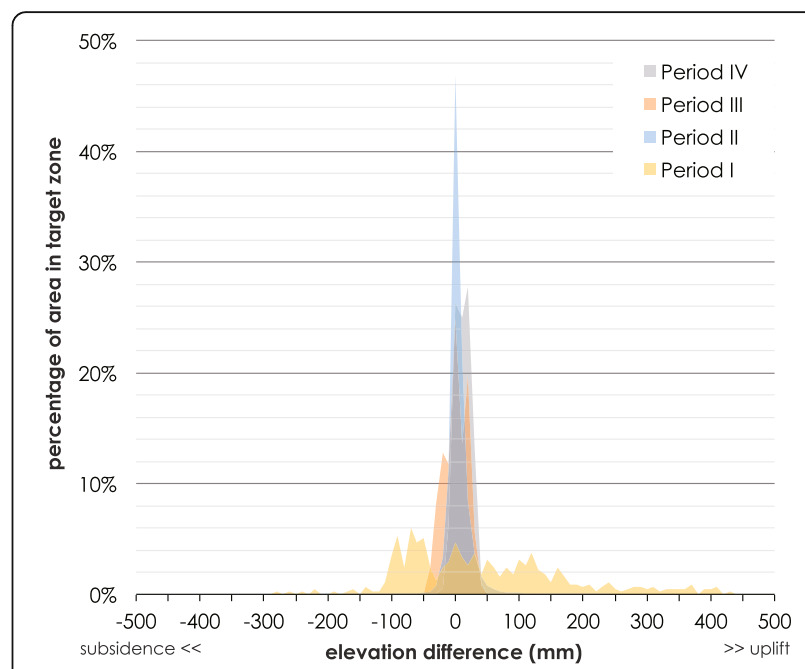

Fig. 6 Distribution of elevation differences within the target zone for each period

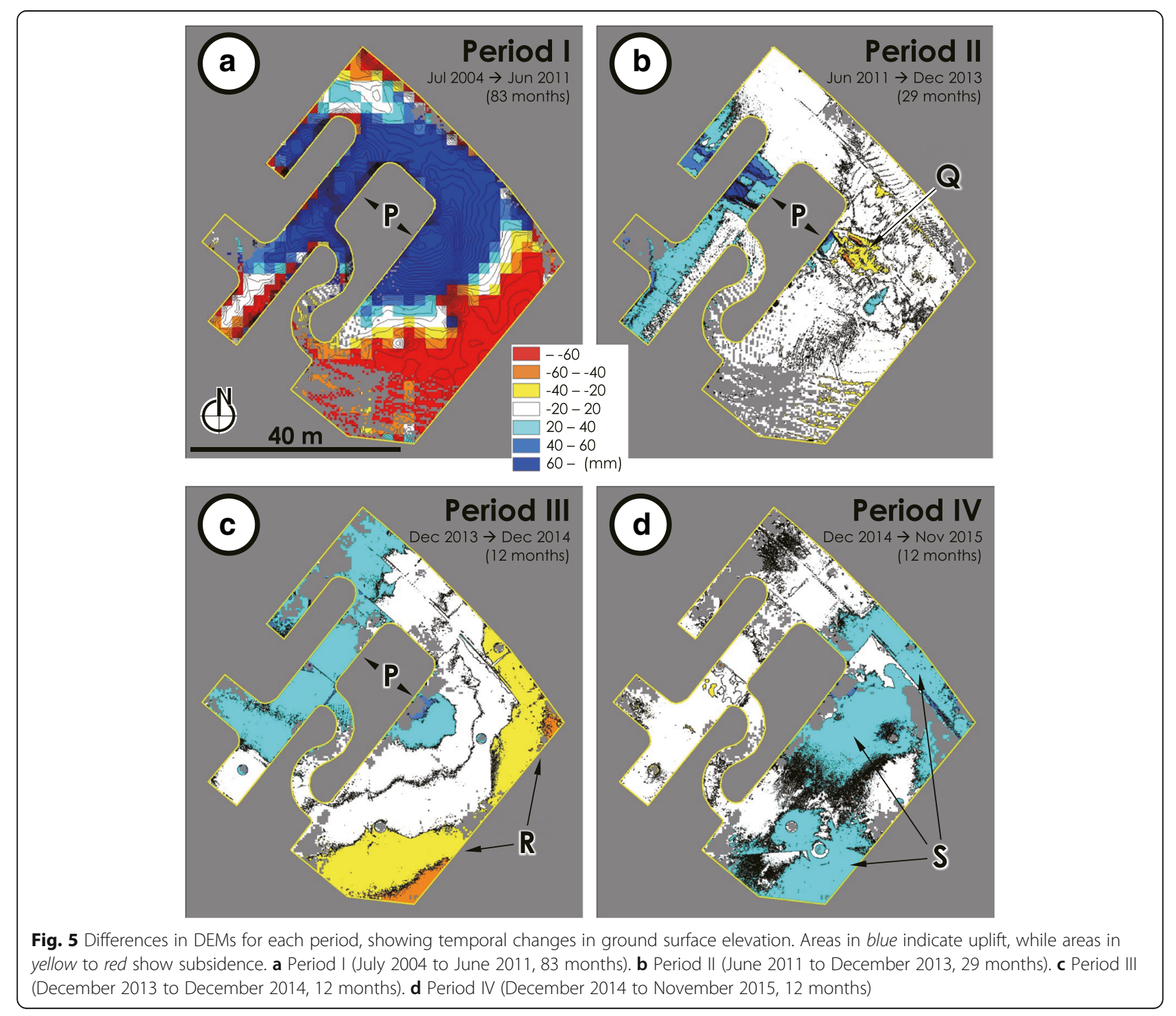


Table 2 Amount and rate of changes in ground surface elevation for each period

\begin{tabular}{|c|c|c|c|c|}
\hline Period & I & $\|$ & III & IV \\
\hline Year & $2004-2011$ & $2011-2013$ & $2013-2014$ & 2014-2015 \\
\hline Duration (months) & 85 & 30 & 12 & 12 \\
\hline Strong earthquakes and maximum acceleration & $\begin{array}{l}2004 \text { Chuetsu }\left(17.5 \mathrm{~cm} / \mathrm{s}^{2}\right) \\
2007 \text { Chuetsu-oki }\left(3.02 \mathrm{~cm} / \mathrm{s}^{2}\right) \\
2011 \text { N Nagano }\left(3.08 \mathrm{~cm} / \mathrm{s}^{2}\right)\end{array}$ & & 2014 Kamishiro $\left(0.22 \mathrm{~cm} / \mathrm{s}^{2}\right)$ & \\
\hline Mean elevation change (mm) & 44.1 & 4.7 & 0.2 & 11.6 \\
\hline Standard deviation of elevation change $(\mathrm{mm})$ & 128.4 & 19.8 & 19.0 & 12.8 \\
\hline 1st percentile & -222.5 & -34.8 & -46.3 & -19.5 \\
\hline 99th percentile & 397.5 & 59.7 & 30.0 & 30.0 \\
\hline Mean rate of elevation change (mm/year) & 6.2 & 1.9 & 0.2 & 11.7 \\
\hline
\end{tabular}

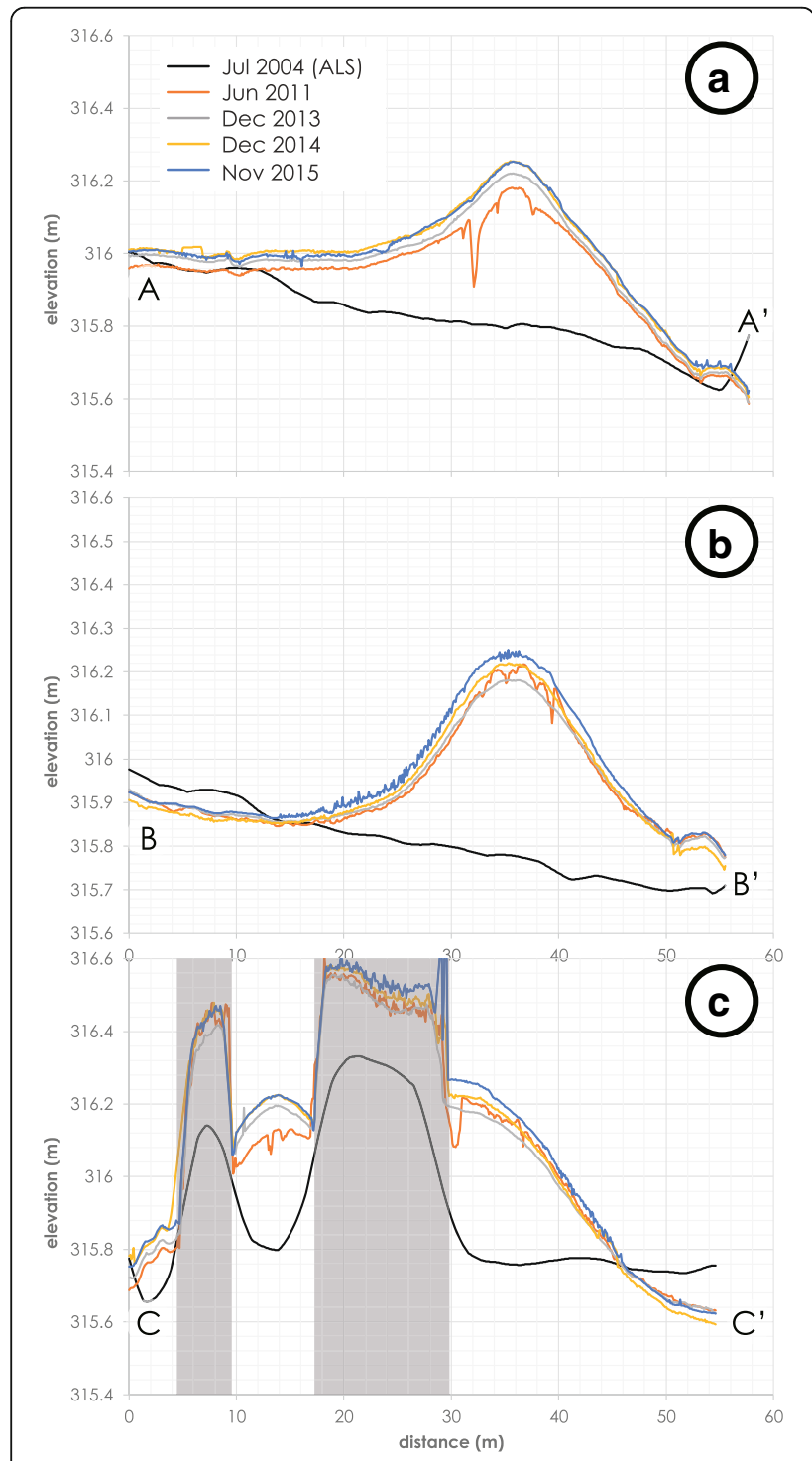

Fig. 7 Topographic profiles along the sections in the target zone. Locations of the three section lines (A-A', B-B', and $\left.C-C^{\prime}\right)$ are shown in Fig. $3 \mathrm{~b}$. The areas outside the target zone are masked with gray in (c) ground surface elevation for each period are described below.

In period I, positive changes in elevation (uplift) are apparent around the center of the target zone where there was a concentration of distinct open cracks forming an elliptical pattern in 2011 ( $\mathrm{P}$ in Fig. 5a). On the other hand, negative changes (subsidence) were also found in the surroundings (Fig. 5a). The most distinct, wide ranging changes in both the positive and negative directions (Fig. 6) are likely due to both the longest elapsed time between measurements (approximately 7 years) and the distinct changes caused by the two large earthquakes, which had accelerations of $17.5 \mathrm{~cm} / \mathrm{s}^{2}$ by 2004 Chuetsu and about $3.0 \mathrm{~cm} / \mathrm{s}^{2}$ by 2007 Chuetsu-oki and 2011 North Nagano (Fig. 5a, Table 2). Over the entire period, uplift seems to have been more dominant than subsidence, resulting in a net elevation change of $44.1 \mathrm{~mm}$ with a maximum uplift of $397.5 \mathrm{~mm}$ (Table 2). Onishi et al. (2009) detected a maximum surface uplift of about $400 \mathrm{~mm}$ in the conspicuous uplift area during 2006 and 2008. Based on the map provided by Onishi et al. (2009), the spatially averaged uplift of this period (2006-2008) in the target zone is visually assumed to be around $200 \pm 50 \mathrm{~mm}$, which is considerably higher than the mean uplift of period I $(44.1 \mathrm{~mm})$ observed in this study (Table 2). Even if the subsided area is excluded, the mean value for only the uplifted area in period $I$ is calculated to be $133 \mathrm{~mm}$, which is still smaller than the assumed mean uplift during 2006-2008. This indicates that considerable subsidence could have occurred in the conspicuous uplift area during the inter-seismic period of 2008-2011. Slight post-earthquake subsidence was actually observed in the area after the 2011 earthquake as described later (period II, Fig. 7b), and such subsidence could have been dominant after the 2007 earthquake. Although the details are unknown, extensive repair work might also explain the ground surface reset after 2008 . In any case, supposing that the ground surface elevation 
after 2008 decreased to the level of the mean uplift in 2006-2008 ( 200 $\mathrm{mm})$ due to either natural subsidence or artificial modification, the uplift directly affected by the 2011 earthquake is assumed to be about $200 \mathrm{~mm}$. This is the maximum value of the potential uplift by the 2011 earthquake. Since separating the effects of the 2007 and 2011 earthquakes precisely is difficult, we assume the potential uplift by the 2011 earthquake to be $0-200 \mathrm{~mm}$.

On the other hand, the large area of subsidence seen in period I (partially reaching $<-200 \mathrm{~mm}$; Figs. 5a and 6, Table 2) was not fully recognized in 2006-2008 by Onishi et al. (2009). They only provided a map showing a limited area of subsidence in the peripheral area, although the exact locations of subsidence were not mentioned and are difficult to identify in their map. The subsidence could have occurred following the 2007 earthquake, as noted above. However, as in the case of period III described later, the subsidence could also be co-seismic. Our data for period I have insufficient temporal resolution to identify the exact timing and amount of such a co-seismic uplift and subsidence in 2007 and 2011, but the possibility that both uplift and subsidence occur at such a local scale as a result of earthquakes is worth further assessment with respect to the co-seismic activity of the mud volcano.

Although the time span of period II (30 months) is longer than periods III and IV (12 months for each), the unchanged area is the largest in period II (white areas in Fig. $5 \mathrm{~b}$ and the highest peak in Fig. 6), likely because of the lack of distinct earthquakes. The mean elevation change was slightly positive $(4.7 \mathrm{~mm}$; Table 2$)$, however. Although this amount of uplift is less than the significant level of change detection limit $(20 \mathrm{~mm})$, the spatial variation in the uplift indicates that partial uplift around the previous cracks ( $\mathrm{P}$ in Fig. $5 \mathrm{~b}$ ) contributed to the net positive change. Note that the large maximum value of uplift in period II (59.7 mm, Table 2) could be due to the difference in the deep crack bottom in 2011 and repaired surface in 2013 and the amount of natural uplift could be a few centimeters (Fig. 7a). In addition, the eastern side shows some negative changes ( $\mathrm{Q}$ in Fig. $5 \mathrm{~b}$ ), which is also apparent in sections $\mathrm{B}-\mathrm{B}^{\prime}$ and $\mathrm{C}-\mathrm{C}^{\prime}$ (Fig. $7 \mathrm{~b}, \mathrm{c}$ ). Although the area where subsidence exceeded the detectable level $(20 \mathrm{~mm})$ is limited, this demonstrates that post-earthquake uplift and subsidence in period II is spatially variable.

In period III, the elliptical pattern of uplift in the central portion is obvious ( $\mathrm{P}$ in Fig. $5 \mathrm{c}$ ), while subsidence also appears on the eastern side ( $\mathrm{R}$ in Fig. $5 \mathrm{c}$ ). The contrast of uplift and subsidence is also clear in profile section $\mathrm{C}-\mathrm{C}^{\prime}$ (Fig. 7c). Compared with periods II and IV, the histogram of elevation change in period III has a relatively wide distribution (Fig. 6), but the mean change is nearly zero (Table 2). This suggests that the 2014 earthquake likely affected the spatial pattern, including both uplift and subsidence. The maximum uplift
$(30 \mathrm{~mm})$ in this period roughly corresponds to that derived from a leveling survey $(46 \mathrm{~mm}$, Kusumoto et al. 2015) but is less than that observed in period I. This may be attributed to the relatively low acceleration experienced in the area $\left(0.22 \mathrm{~cm} / \mathrm{s}^{2}\right)$ in the 2014 earthquake (Table 2).

Unlike the earlier periods, period IV shows less change in the central portion, having no detectable differences $( \pm 20 \mathrm{~mm}$ ), while it shows positive surface changes (uplift) on the eastern side ( $\mathrm{S}$ in Fig. 5d). Though not exceeding the significant level of $\pm 20 \mathrm{~mm}$, slight subsidence is also observed in the southwestern side of profile section $\mathrm{A}-\mathrm{A}^{\prime}$ (Fig. 5a). Thus, the spatial pattern of uplift and subsidence in this period is quite different from the others. Furthermore, the histogram of elevation change in period IV shows a biased positive trend (Fig. 6), and the mean value of uplift is large $(11.6 \mathrm{~mm}$; Table 2$)$. In turn, detectable subsidence areas are almost absent in period IV (Fig. 5d). The mean uplift rate of period IV (11.7 $\mathrm{mm}$ /year for 12 months) is considerably higher than that of period II (1.9 mm/year for 30 months). Both are assumed to be gradual since there were no distinct earthquakes in either period.

\section{Formation of surface fractures by earthquakes}

In the earthquake-affected periods I and III, the areas of uplift show elliptical spatial patterns (Fig. 5a, c). The cumulative changes in surface elevation after the first TLS measurement, from 2011 to 2015, also reflect this elliptical pattern, whose major axis direction was $\mathrm{W} 36^{\circ} \mathrm{N}$ (Fig. 8). Figure 8 also shows the mapped crack lines on the paved ground surface found in June 2011, whose average orientation is $\mathrm{W} 37.5^{\circ} \mathrm{N}$, almost the same as that of the elliptic uplift. This may reflect the underground fluid dynamics of the mud, likely caused by pressure variability triggered by the earthquakes. Here, we discuss the fracture patterns and pressure estimates related to the earthquakes. As noted, in these earthquake-affected periods, there were not only areas of uplift but also areas of subsidence, particularly in the southeastern side of the target zone. Although Onishi et al. (2009) argued that because no significant surficial change was present through the 2007 earthquake, the southeastern area is unaffected by the mud volcano activity, the presence of subsidence found in this study may suggest that the mud volcano affects the surrounding area extensively, inducing subsurface lateral migration of fluid mud. However, the target zone of this study does not seem to cover the entire peripheral area that may experience subsidence. It does include the area with conspicuous uplift that exhibits more clear features, comprising the elliptical uplift pattern and surficial fractures. Therefore, we simply focus on the pressure mechanisms of uplift and fractures. 


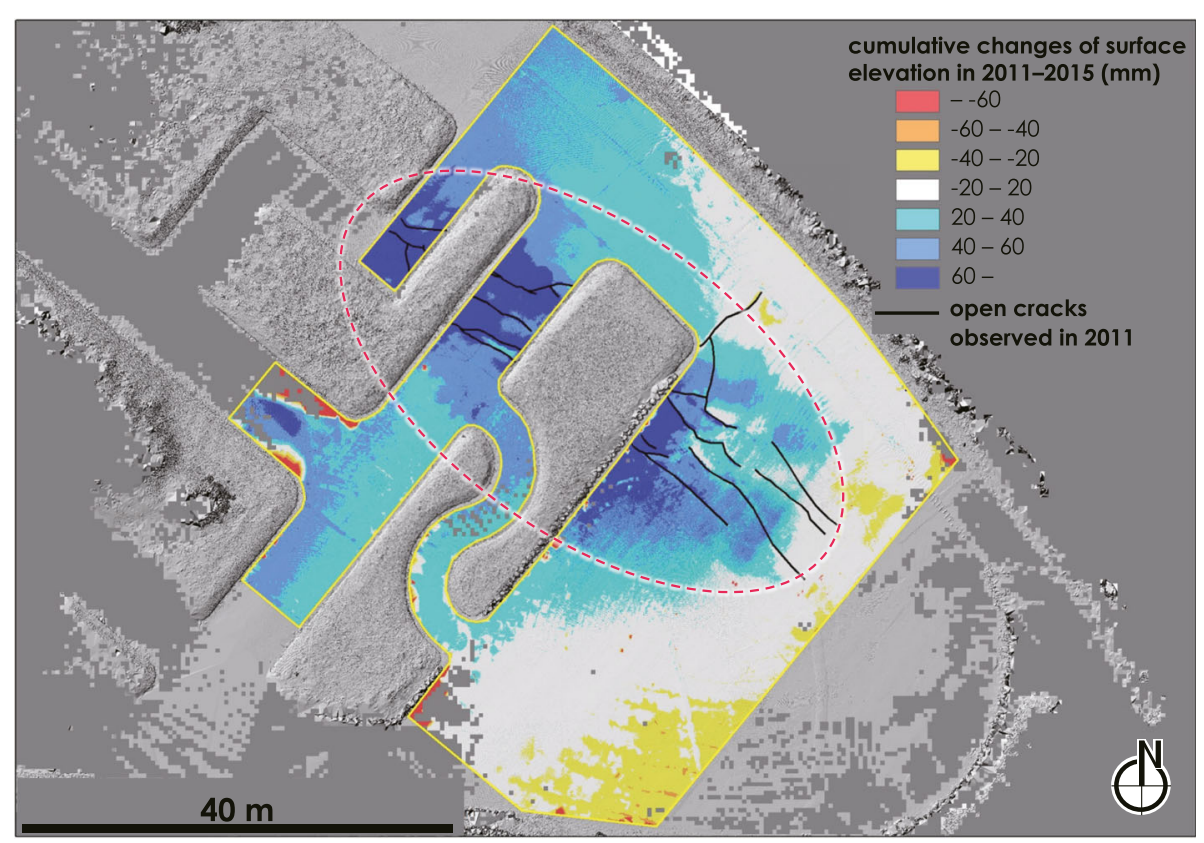

Fig. 8 Cumulative surface elevation changes throughout periods II-IV based on TLS-derived data. Traces of the open cracks observed in 2011 are shown as solid black lines. Dashed line indicates the elliptical uplift zone

Although Kusumoto et al. (2015) pointed out that the uplift area was elliptical with major and minor axes of about 80 and $40 \mathrm{~m}$, respectively, the conspicuous, essential uplift area is narrower. In previous studies, the conspicuous uplift areas were reported in the same location, and they have a common size with major and minor axes of about 40 and $30 \mathrm{~m}$, respectively. In order to focus on the mechanisms of uplift and fracture formation observed in this study, we modeled the uplift area using $a=20 \mathrm{~m}$ and $b=15 \mathrm{~m}$ for Eqs. (1)-(10).

In the study area, an elastic surface layer, estimated to be about $1 \mathrm{~m}$ thick, was identified using the surface wave method, which estimates distributions of shearwave velocity by surface wave inversion (Onishi et al. 2009). In addition, because the layer is at the surface and its elastic constants have not been measured, we assumed a low Young's modulus of $1 \mathrm{GPa}$ and a typical Poisson's ratio of 0.25 for the layer (e.g., Bell 2000).

We first estimated the magnitude of an overpressure that could form the uplift that potentially reached $200 \mathrm{~mm}$, caused by the 2011 North Nagano Prefecture Earthquake. To assess the maximum uplift, we took $x=$ $y=0$ in Eq. (1) and, with Eqs. (1), (2), and (3), obtained the equation that gives the maximum uplift,

$$
u_{z \max }=\frac{12\left(1-v^{2}\right) p}{E h^{3}}\left(\frac{24}{a^{4}}+\frac{16}{a^{2} b^{2}}+\frac{24}{b^{4}}\right)^{-1}
$$

We rewrite this equation as

$$
p=\frac{E h^{3} u_{z_{-} \max }}{12\left(1-v^{2}\right)}\left(\frac{24}{a^{4}}+\frac{16}{a^{2} b^{2}}+\frac{24}{b^{4}}\right),
$$

and by taking $a=20 \mathrm{~m}, b=15 \mathrm{~m}, v=0.25, h=1.0 \mathrm{~m}$, $E=1 \mathrm{GPa}$, and $u_{z_{-} \max }=200 \mathrm{~mm}$, we obtained $p=$ $14.26 \mathrm{kPa}$ as the overpressure that gives an uplift of $200 \mathrm{~mm}$.

In Fig. 9a, we show the vertical displacement field caused by the overpressure $(p=14.26 \mathrm{kPa})$. The calculated vertical displacement field turns out to be consistent with the observed vertical displacement field.

Figure $9 \mathrm{~b}$ shows the distribution of the principal stress axes around the center part of the uplift. The maximum principal stress axes, $\sigma_{1}$, are distributed along the major axis of the elliptical uplift area, and the minimum principal stress axes are perpendicular to $\sigma_{1}$, so they are distributed along the minor axis of the elliptical uplift area. This indicates that if the minimum principal stress exceeded the tensile strength of the medium, open fractures (cracks) would appear at the surface and their strike directions would correspond to the direction of the maximum principal stress axis, which is the major axis of the elliptical uplift area.

Fractures observed at the surface are distributed along the major axis of the elliptical uplift area (Fig. 8). This distribution pattern is consistent with the direction of the maximum principal stress axis shown in Fig. 9b. In addition, the observed fractures are basically open fractures, including some strike-slip fracturing, and it is known that the in situ tensile strength of most of the 


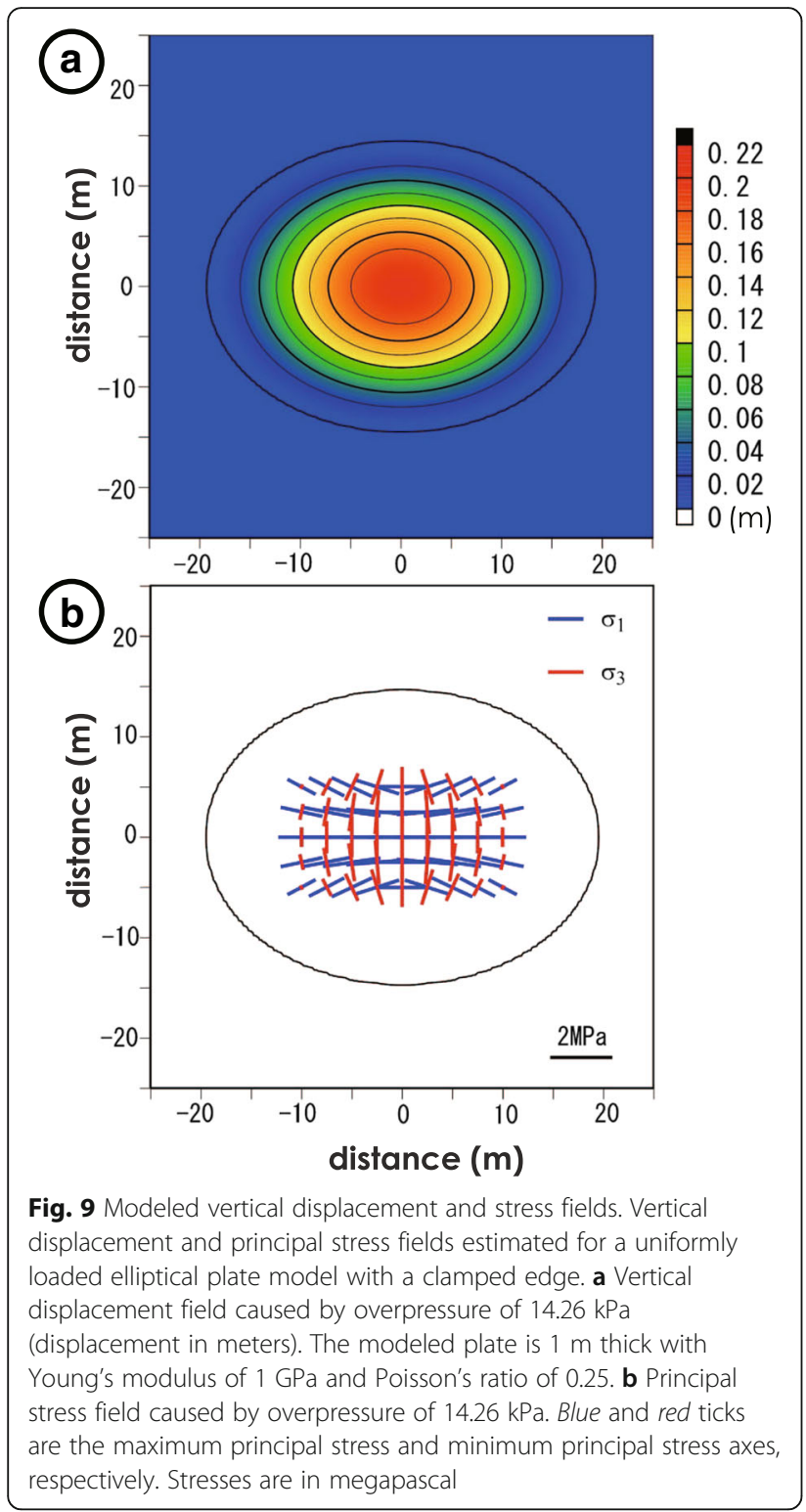

rocks is between 0.5 and $6 \mathrm{MPa}$ (e.g., Haimson and Rummel 1982; Amadei and Stephansson 1997; Schultz 1997; Gudmundsson 2011). The general tensile strength of asphalt mixtures is known to be around $4 \mathrm{MPa}$ when colder than $0{ }^{\circ} \mathrm{C}$ but less than $1 \mathrm{MPa}$ when the temperature is more than $10{ }^{\circ} \mathrm{C}$ (Yoshida et al. 2001). Since the maximum calculated stress $\sigma_{3}$ was about 1.5 MPa (Fig. 9b), an uplift of $200 \mathrm{~mm}$ can form fractures at the paved asphalt surface, particularly in higher summer temperatures. From the observed data and simulated results, we can conclude that an elliptical uplift area potentially reaching $200 \mathrm{~mm}$ can be explained by an overpressure change as high as $14.26 \mathrm{kPa}$. Furthermore, we can conclude that fractures were formed as the minimum principal stress $(>1.5 \mathrm{MPa})$ exceeded the tensile strength at this elliptical area surface and were propagated in the direction of the maximum principal stress axes. In turn, assuming that the tensile strength of the paved asphalt surface is as low as $1 \mathrm{MPa}$, fractures could have formed with an uplift of $133 \mathrm{~mm}$ or more. Although the exact uplift amount by the 2011 earthquake is unknown, the calculation above indicates the potential uplift at this time, given the extensive formation of fractures, to be approximately $100-200 \mathrm{~mm}$.

Although Onishi et al. (2009) does not report on the occurrence of fractures, fractures would have formed and been observed at the surface because the uplift, which exceeded $400 \mathrm{~mm}$, would have produced a minimum principal stress of more than $3 \mathrm{MPa}$. On the other hand, since it is estimated that the uplift of $46 \mathrm{~mm}$ caused by the 2014 Kamishiro Fault Earthquake (Kusumoto et al. 2015) would have produced a minimum principal stress of $0.35 \mathrm{MPa}$, the uplift would not have formed open fractures if the pavement's tensile strength at the site were $0.5 \mathrm{MPa}$ or higher. However, many open fractures were actually observed at the surface, and their distribution pattern was similar to the pattern shown in Fig. 8. Although the tensile strength of asphalt material can drop to $0.2-0.4 \mathrm{MPa}$ at a temperature of around $20{ }^{\circ} \mathrm{C}$ (Yoshida et al. 2001), the ground surface temperature of the site on the autumn night of the earthquake (22:08 on November 22) could not have been that high. From observations of open fracture formation caused by such low tensile stress, we can infer a decrease of the tensile strength at this site, including in the subsurface rocks, caused by repeated tensile fracturing, since conspicuous uplifts by earthquakes and fractures have always been formed in the same area, at least until the 2014 earthquake (Fig. 5).

\section{Seismic and inter-seismic surface deformations}

The spatial pattern of the mud volcano's vertical displacement was found to be different for the earthquakeaffected periods (I and III) and the inter-seismic periods (II and IV). The elliptical pattern of the uplift and the subsidence distribution, as well as the formation of surface fractures, characterizes the earthquake-affected periods (Fig. 5a, c), whereas the gradual changes in the inter-seismic periods are spatially variable but result in the dominance of uplift (Table 2).

Although the ground surface tends to generally rise during the inter-seismic period, the patterns of surface uplift are different for period II and period IV. In period II, the uplift pattern follows the crack fractures formed by the 2011 North Nagano Prefecture Earthquake, i.e., the largest uplifts are observed along the crack lines (Figs. 5b and 7a). Similarly, the center of uplift is concentrated in the northwestern area in periods I-III. In contrast, a widespread uplift pattern in period IV was found in the eastern side of the target area (Figs. 5d and 
7b), while fewer changes were observed in the northwestern area where the conspicuous uplift had been previously observed (Figs. $5 \mathrm{~d}$ and $7 \mathrm{a}$ ). This shift in the location of uplift may indicate a change in local subsurface fluid dynamics after the 2014 Nagano-ken Kamishiro Fault Earthquake. The earthquake could have triggered a change in the local pressure field within the domain of the mud volcano.

A large-scale change in the center of the activity of a mud volcano may be related to the dynamics constrained by the lithological and tectonic structures that exist at depths of hundreds of meters to kilometers (e.g., Kopf 2002; Planke et al. 2003; Istadi et al. 2009; Shinya and Tanaka 2009). Using the controlled source audiofrequency magneto-telluric (CSAMT) method, low resistivity areas indicating mud chambers, located several hundred meters to kilometers from the surface, have been found around the Murono mud volcano (Suzuki et al. 2009). However, since the observed surface deformations in the Murono mud volcano are small, it is more likely that the slight change of several meters in the surface activity observed for the Murono mud volcano is related to shallower subsurface structure within tens of meters in depth. In fact, very shallow low-velocity layers ( 1 to $5 \mathrm{~m}$ deep or deeper than $13 \mathrm{~m}$ ) were observed by Onishi et al. (2009).

Although Kusumoto et al. (2014) suggested overpressure changes in fluid mud flow were a direct source of ground surface deformation during the quiescent phase, the details of the subsurface fluid dynamics remain to be clarified by geophysical measurements, and the relationship between fluid mud flow and surface deformation has not yet been directly revealed. As shown in this paper, subtle changes in the surface topography indicate changes in subsurface fluid activity, providing a guideline for further geophysical analyses. Also, in order to obtain a clearer pattern image of the shift of the central portion of uplift of the mud volcano, it is necessary to carry out repeated, widespread additional topographic measurements to monitor the activity in the following years.

\section{Conclusions}

We performed TLS measurements on the small mud volcano at Murono, central Japan, revealing the spatial variations of its vertical displacements at the centimeter scale. The detection of such spatially variable small-scale changes including both central uplift and peripheral subsidence, as well as the mapping of small topographic features including open cracks, enabled us to discuss the detailed changes in both seismic and inter-seismic deformations of the ground surface of the mud volcano. We also quantified the magnitude of the pressure field induced by earthquakes by modeling the pressure required to produce the cracks observed in the conspicuous, elliptical uplift area. The cracks suggested the presence of a local pop-up of subsurface fluid induced by the earthquakes, as well as the weakening of surface materials by repeated uplift. The uplift pattern in the quiescent period was found to be similar during periods I-III but changed after the 2014 Nagano-ken Kamishiro Fault Earthquake, suggesting changes in subsurface fluid dynamics after that earthquake. Further topographic measurements, as well as other geophysical data, are expected to provide a better understanding of the localscale subsurface mechanisms of the mud volcano. In particular, although the modeled uplift and fracture formation were limited to a small conspicuous area $(20 \mathrm{~m} \times 15 \mathrm{~m})$, more widespread modeling efforts that include the surrounding subsidence area will further clarify the mechanisms of the mud volcano activity, for which expanding the target area of measurement would be necessary. Increased frequency of topographic measurements, particularly after a strong earthquake, would also be helpful in revealing detailed temporal changes in the mud volcano.

\section{Abbreviations}

a.s.l.: Above sea level; ALS: Airborne laser scanning; CSAMT: Controlled source audio-frequency magneto-telluric; DEM: Digital elevation model; DTM: Digital terrain model; GIS: Geographic information system; GNSS: Global navigation satellite system; ICP: Iterative closest point; InSAR: Interferometric synthetic aperture radar; TIN: Triangular irregular network; TLS: Terrestrial laser scanning; UTM: Universal Transverse Mercator

\section{Acknowledgements}

We thank the editor and the two anonymous reviewers for their critical but constructive comments, which greatly improved the manuscript. We would like to thank Editage (https://www.editage.jp) and FORTE (https://www.fortescience.co.jp/) for English language editing. This work is supported by JSPS KAKENHI Grant Number JP25702014 and is a part of the joint research of CSIS, The University of Tokyo.

\section{Funding}

Not applicable

\section{Availability of data and materials}

The data used in this paper are available for research purposes at JoRAS (Joint Research Assist System): https://joras.csis.u-tokyo.ac.jp/dataset/show/id/ 15003201000 .

\section{Authors' contributions}

YSH performed the TLS measurements in the field and analyzed the data, as well as drafting this manuscript. SK carried out numerical modeling, drafted the manuscript, and obtained permission for the field survey. NM planned the initial field measurements and discussed the results we obtained. All authors read and approved the final manuscript.

\section{Competing interests}

The authors declare that they have no competing interests.

\section{Author details}

'Center for Spatial Information Science, The University of Tokyo, 5-1-5 Kashiwanoha, Kashiwa, Chiba 277-8568, Japan. ${ }^{2}$ Graduate School of Science and Engineering for Research, University of Toyama, 3190 Gofuku, Toyama City, Toyama 930-8555, Japan. ${ }^{3}$ Graduate School of Education, Okayama University, 3-1-1 Tsushimanaka, Okayama City, Okayama 700-8530, Japan. 
Received: 31 May 2016 Accepted: 23 December 2016 Published online: 07 February 2017

\section{References}

Amadei B, Stephansson O (1997) Rock stress and its measurement. Chapman \& Hall, London

Antonielli B, Monserrat O, Bonini M, Righini G, Sani F, Luzi G, Feyzullayev A, Aliyev C (2014) Pre-eruptive ground deformation of Azerbaijan mud volcanoes detected through satellite radar interferometry (DInSAR). Tectonophysics 637: 163-177. doi:10.1016/j.tecto.2014.10.005

Bell FG (2000) Engineering properties of rocks, 4th edn. Blackwell, Oxford

Bergevin R, Soucy M, Qagnon H, Laurendeau D (1996) Towards a general multiview registration technique. IEEE Trans Pattern Anal Mach Intell 18:540-547. doi:10.1109/34.494643

Besl PJ, McKay ND (1992) A method for registration of 3-D shapes. IEEE Trans Pattern Anal Mach Intell 14:239-256. doi:10.1109/34.121791

Brown KM (1990) The nature and hydrogeologic significance of mud diapirs and diatremes for accretionary systems. J Geophys Res 95:8969-8982. doi:10. 1029/JB095iB06p08969

Chigira M, Tanaka K (1997) Structural features and the history of mud volcanoes in southern Hokkaido, northern Japan. J Geol Soc Japan 103:781-791. doi: 10. 5575/geosoc.103.781

DeLong SB, Lienkaemper JJ, Pickering AJ, Avdievitch NN (2015) Rates and patterns of surface deformation from laser scanning following the South Napa earthquake, California. Geosphere 11:1-17. doi:10.1130/GES01189.1

Dimitrov LI (2002) Mud volcanoes - the most important pathway for degassing deeply buried sediments. Earth Sci Rev 59:49-76. doi: 10.1016/500128252(02)00069-7

Dimitrov LI (2003) Mud volcanoes-a significant source of atmospheric methane. Geo-Mar Lett 23:155-161. doi:10.1007/s00367-003-0140-3

Doshida S, Chigira M, Nakamura T (2007) Morphological analysis of shallow landslides on mud volcanoes by using airborne laser scanner. Trans J.jn Geomorphol Union 28:23-39

Etiope G (2005) Methane emission from mud volcanoes. In: Martinelli G, Panahi B (eds) Mud volcanoes, Geodyn. Seism. Springer-Verlag, Berlin/Heidelberg, pp $141-146$

Etiope G, Nakada R, Tanaka K, Yoshida N (2011) Gas seepage from Tokamachi mud volcanoes, onshore Niigata Basin (Japan): origin, post-genetic alterations and $\mathrm{CH} 4-\mathrm{CO} 2$ fluxes. Appl Geochem 26:348-359. doi:10.1016/j.apgeochem. 2010.12.008

Feyzullayev AA, Kadirov FA, Aliyev CS (2005) Mud volcano model resulting from geophysical and geochemical research. In: Martinelli G, Panahi B (eds) Mud volcanoes, Geodyn. Seism. Springer-Verlag, Berlin/Heidelberg, pp 251-262

Fukushima Y, Mori J, Hashimoto M, Kano Y (2009) Subsidence associated with the LUSI mud eruption, East Java, investigated by SAR interferometry. Mar Pet Geol 26:1740-1750. doi:10.1016/j.marpetgeo.2009.02.001

Gudmundsson A (2011) Rock fractures in geological processes. Cambridge Univ. Press, Cambridge

Haimson BC, Rummel F (1982) Hydrofracturing stress measurements in the Iceland Research Drilling Project drill hole at Reydarfjordur, Iceland. J Geophys Res Solid Earth 87:6631-6649. doi:10.1029/JB087iB08p06631

Hayakawa YS, Oguchi T (2016) Applications of terrestrial laser scanning in geomorphology (in Japanese with English abstract). J Geogr (Chigaku Zasshi) 125:299-324. doi:10.5026/jgeography.125.299

Hayakawa YS, Kusumoto S, Matta N (2016) Application of terrestrial laser scanning for detection of ground surface deformation in small mud volcano (Murono, Japan). Earth Planets Space 68:114. doi:10.1186/s40623-016-0495-0

Heritage GL, Large ARG (2009) Laser scanning for the environmental sciences. Wiley-Blackwell, Oxford

Higgins G, Saunders J (1974) Mud volcanoes: their nature and origin. Verh Naturfsch Ges Bersel 84:101-152

Hovland M, Hill A, Stokes D (1997) The structure and geomorphology of the Dashgil mud volcano, Azerbaijan. Geomorphology 21:1-15. doi:10.1016/ S0169-555X(97)00034-2

Istadi BP, Pramono GH, Sumintadireja P, Alam S (2009) Modeling study of growth and potential geohazard for LUSI mud volcano: East Java, Indonesia. Mar Pet Geol 26:1724-1739. doi:10.1016/j.marpetgeo.2009.03.006

Japan Meteorological Agency (2016) Monthly climate: AMEDAS 54676Tokamachi. http://www.data.jma.go.jp/obd/stats/etrn/view/nml_amd_ym. php?prec_no $=54 \&$ block_no $=0537 \& y e a r=\&$ month $=\& d a y=\& v i e w=$. Accessed 30 Sep 2016.
Judd A (2005) Gas emissions from mud volcanoes. In: Martinelli G, Panahi B (eds) Mud volcanoes, Geodyn. Seism. Springer-Verlag, Berlin/Heidelberg, pp 147-157

Kopf AJ (2002) Significance of mud volcanism. Rev Geophys 40:1005. doi: 10. 1029/2000RG000093

Kusumoto S, Sudo K, Kawabata M, Uda T, Fukuda Y (2014) Vertical movement during the quiescent phase of the Murono mud volcano, Niigata, Japan. Earth Planets Space 66:14. doi:10.1186/1880-5981-66-14

Kusumoto S, Hamamoto T, Fukuda Y, Takahashi A (2015) Vertical movements of the Murono mud volcano in Japan caused by the Naganoken Kamishiro Fault Earthquake in 2014. Earth Planets Space 67:53. doi:10. 1186/s40623-015-0223-1

Lane SN, Westaway RM, Hicks DM (2003) Estimation of erosion and deposition volumes in a large gravel-bed, braided river using synoptic remote sensing. Earth Surf Process Landf 28:249-271. doi: 10.1002/esp.483

Manga M, Brumm M, Rudolph ML (2009) Earthquake triggering of mud volcanoes. Mar Pet Geol 26:1785-1798. doi:10.1016/j.marpetgeo.2009.01.019

Martinelli G, Dadomo A (2005a) Mud volcano monitoring and seismic events. In: Martinelli G, Panahi B (eds) Mud volcanoes, Geodyn. Seism. Springer-Verlag, Berlin/Heidelberg, pp 187-199

Martinelli G, Dadomo A (2005b) Geochemical model of mud volcanoes from reviewed worldwide data. In: Martinelli G, Panahi B (eds) Mud Volcanoes, Geodyn. Seism. Springer-Verlag, Berlin/Heidelberg, pp 211-220

Matta N, Hayakawa YS, Hori K, Kuo Y-T, Sugito N (2012) Uplift of the Matsudai mud volcano associated with the earthquake near the border of Nagano and Niigata Prefectures, measured by 3D laser scanner (in Japanese). Trans Jpn Geomorphol Union 33:94-95

Mazzini A (2009) Mud volcanism: processes and implications. Mar Pet Geol 26: 1677-1680. doi:10.1016/j.marpetgeo.2009.05.003

Mellors R, Kilb D, Aliyev A, Gasanov A, Yetirmishli G (2007) Correlations between earthquakes and large mud volcano eruptions. J Geophys Res Solid Earth 112:B04304. doi: 10.1029/2006JB004489.

Milan DJ, Heritage GL, Large ARG, Fuller IC (2011) Filtering spatial error from DEMs: implications for morphological change estimation. Geomorphology 125:160-171. doi:10.1016/j.geomorph.2010.09.012

Milkov AV (2000) Worldwide distribution of submarine mud volcanoes and associated gas hydrates. Mar Geol 167:29-42. doi:10.1016/50025$3227(00) 00022-0$

Milkov AV (2005) Global distribution of mud volcanoes and their significance in petroleum exploration as a source of methane in the atmosphere and hydrosphere and as a geohazard. In: Martinelli G, Panahi B (eds) Mud Volcanoes, Geodyn. Seism. Springer-Verlag, Berlin/Heidelberg, pp 29-34

Moerz T, Fekete N, Kopf A, Brueckmann W, Kreiter S, Huehnerbach V, Masson D, Hepp DA, Schmidt M, Kutterolf S, Sahling H, Abegg F, Spiess V, Suess E, Ranero C (2005) Styles and productivity of mud diapirism along the Middle American margin. In: Martinelli G, Panahi B (eds) Mud Volcanoes, Geodyn. Seism. Springer-Verlag, Berlin/Heidelberg, pp 49-76

Mori J, Kano Y (2009) Is the 2006 Yogyakarta earthquake related to the triggering of the Sidoarjo, Indonesia mud volcano? Chigaku Zasshi (J Geogr) 118:492498. doi:10.5026/jgeography.118.492

Nakahara I, Shibuya T, Tsuchida E, Kasano H, Tsuji T, Inoue H (2001) Handbook of elasticity (in Japanese). Asakura Shoten, Tokyo

National Research Institute for Earth Science and Disaster Resilience (2016) Strong-motion seismograph networks (K-NET, KiK-net). http://www.kyoshin. bosai.go.jp/ [accessed 30 Aug 2016]

Noda H (1962) The geology and paleontology of the environs of Matsunoyama, Niigata Prefecture, with reference to the so-called black shale (in Japanese with English abstract). Sci Rep Res Inst Tohoku Univ 2:199-236

Olsen MJ, Johnstone E, Driscoll N, Ashford SA, Kuester F (2009) Terrestrial laser scanning of extended cliff sections in dynamic environments: parameter analysis. J Surv Eng 135:161-169

Onishi K, Sanada Y, Yokota T, Tokunaga T, Mogi K, Safani J, O'Neill A (2009) Investigation of subsurface s-wave velocity structures beneath a mud volcano in the Matsudai-Murono District by surface wave method (in Japanese with English abstract). Chigaku Zasshi (J Geogr) 118:390-407. doi: 10.5026/jgeography. 118.390

Panahi B (2000) On spatial and time correlation of earthquakes and mud volcano eruptions and seismic regime of Azerbaijan-Caspian Sea region. Geophys News Azerbaijan 1:26-29

Panahi BM (2005) Mud volcanism, geodynamics and seismicity of Azerbaijan and the Caspian Sea region. In: Martinelli G, Panahi B (eds) Mud Volcanoes, Geodyn. Seism. Springer-Verlag, Berlin/Heidelberg, pp 89-104 
Planke S, Svensen H, Hovland M, Banks DA, Jamtveit B (2003) Mud and fluid migration in active mud volcanoes in Azerbaijan. Geo-Mar Lett 23:258-268. doi:10.1007/s00367-003-0152-z

Rudolph ML, Manga M (2012) Frequency dependence of mud volcano response to earthquakes. Geophys Res Lett 39:1-5. doi:10.1029/2012GL052383

Schultz RA (1997) Displacement-length scaling for terrestrial and Martian faults: implications for Valles Marineris and shallow planetary grabens. J Geophys Res Solid Earth 102(B6):12009-12015. doi: 10.1029/97JB00751

Shakirov R, Obzhirov A, Suess E, Salyuk A, Biebow N (2004) Mud volcanoes and gas vents in the Okhotsk Sea area. Geo-Mar Lett 24:140-149. doi:10.1007/ s00367-004-0177-y

Shinya T, Tanaka K (2009) Origin of materials erupting from mud volcano in Tokamachi City, Niigata Prefecture, Central Japan (in Japanese with English abstract). Chigaku Zasshi (J Geogr) 118:340-349. doi:10.5026/ jgeography.118.340

Suzuki K, Tokuyasu S, Tanaka K (2009) Underground structure of mud volcanoes in Tokamachi City, Niigata Prefecture determined by electromagnetic exploration, and geographical and geological surveys (in Japanese with English abstract). Chigaku Zasshi (J Geogr) 118:373-389. doi: 10.5026/ jgeography.118.373

Takeuchi K, Yoshikawa T, Kamai T (2000) Geology of the Matsunoyama Onsen district with geological map at 1:50,000 (in Japanese with English abstract). Geological Survey of Japan, Tsukuba

Teza G, Galgaro A, Zaltron N, Genevois R (2007) Terrestrial laser scanner to detect landslide displacement fields: a new approach. Int J Remote Sens 28:34253446. doi:10.1080/01431160601024234

Timoshenko SP, Woinowsky-Krieger S (1959) Theory of plates and shells, 2nd edn. McGraw-Hill, New York

Topcon (2010) User manual: laser scanner GLS-1500 series (in Japanese), Topcon, Tokyo

Trimble Navigation Limited (2012) Datasheet Trimble TX5 scanner, Trimble Inc., Sunnyvale

Wang C-Y, Manga M (2010) Mud volcanoes. Earthquakes Water - Lect. Notes Earth Sci. 114. Springer, Berlin/Heidelberg, pp 33-43

Whitworth MZ, Giles D, Anderson I (2006) Terrestrial laser scanning for applied geoscience studies in the urban environment. In: Tenth IAEG Congr (ed) The Geological Society of London. The Geological Society of London, Nottingham, pp 1-9

Yokota T, Onishi K, Sanada Y (2008) Geophysical explorations of shallow structure of mud volcano using a ground penetrating radar system in Matsudai, Tokamachi City, Niigata Japan (in Japanese). Chishitsu News 644:25-32

Yoshida T, Moriyoshi A, Takano S (2001) Fracture properties of asphalt mixture in tension and application (in Japanese with English abstract). Sekiyu Gakkaishi 44:312-316

\section{Submit your manuscript to a SpringerOpen ${ }^{\circ}$ journal and benefit from:}

- Convenient online submission

- Rigorous peer review

- Immediate publication on acceptance

- Open access: articles freely available online

- High visibility within the field

- Retaining the copyright to your article

Submit your next manuscript at $>$ springeropen.com 